\title{
ANÁLISE DA VARIAÇÃO ESPACIAL E TEMPORAL DO ÍNDICE DE VEGETAÇÃO E SUA RELAÇÃO COM PARÂMETROS CLIMÁTICOS NA BACIA HIDROGRÁFICA DO ALTO CURSO DO RIO PARAÍBA, ESTADO DA PARAÍBA, BRASIL
}

\author{
ANALYSIS OF THE SPATIAL AND TEMPORAL VARIATIONS IN THE \\ VEGETATION INDEX AND ITS RELATIONSHIP WITH CLIMATE \\ PARAMETERS IN THE HYDROGRAPHIC BASIN OF THE UPPER REACHES OF \\ THE RIVER PARAÍBA, STATE OF PARAÍBA, BRAZIL
}

\begin{abstract}
ANÁLISIS DE LOS CAMBIOS EN EL ESPACIO Y TEMPORAL DE ÍNDICE DE VEGETACIÓN Y SU RELACIÓN CON LOS PARÁMETROS DEL CLIMA EN LA CUENCA DEL ALTO CURSO RÍO PARAÍBA, ESTADO DE PARAÍBA, BRASIL
\end{abstract}

Telma Lucia Bezerra Alves - Universidade Federal de Campina Grande - Campina Grande - Paraíba - Brasil telmalu@yahoo.com.br

Pedro Vieira de Azevedo - Universidade Federal de Campina Grande - Campina Grande - Paraíba - Brasil

pvieira@dca.ufcg.edu.br

\section{Resumo}

0 presente estudo teve como objetivo analisar a variação espaço-temporal do índice de vegetação da diferença normalizada (IVDN), do índice de vegetação ajustado para o solo (IVAS) e a relação com parâmetros climáticos na bacia hidrográfica do alto curso do Rio Paraíba, que engloba total ou parcialmente, 18 municípios, distribuídos nas microrregiões do Cariri Ocidental e Oriental do estado da Paraíba. Foram utilizadas 168 imagens MODIS (Moderate Resolution Imaging Spectro Radiometer), correspondentes aos 12 meses do ano no período de 2000 a 2013, para obtenção dos índices de vegetação que posteriormente foram correlacionados comdados de precipitação pluvial e temperatura média do ar. Utilizou-se o método de krigagem para espacialização de dados e geração de mapas temáticos. 0s principais resultados evidenciam que os valores médios do índice de vegetação decrescem de noroeste e nordeste para a porção central da bacia, com valores mínimos no município de Congo. 0 índice de vegetação foi espacial e temporalmente heterogêneo 0 que corresponde às características climáticas regionais. 0 ano seco de 2013 apresentou valores de índice de vegetação inferiores ao ano chuvoso de 2008, mas ainda assim há variação espaço-temporal e intra-anual. Houve correlações negativas entre os índices de vegetação e a temperatura do ar e correlações positivas, mais significativas, com a precipitação pluvial.

Palavras-chave: caatinga, precipitação pluvial, temperatura do ar, sensoriamento remoto.

\section{Abstract}

This study aimed to analyze the spatial and temporal variation of the normalized difference vegetation index (NDVI) and the soil-adjusted vegetation index (SAVI), as well as the relationship among climate parameters in the basin of the upper reaches of the River Paraíba, which includes all or some of the eighteen municipalities, distributed in the regions of Western and Eastern Cariri of Paraíba state. 168 MODIS images were used 
(moderate resolution imaging spectroradiometer), corresponding to the twelve months of the year from 2000 to 2013 , to obtain the vegetation indexes, which were then correlated with rainfall and average air temperature data. We used the kriging method of spatial data and thematic maps. The main results show that the average score of the vegetation index decreases from the northwest and northeast to the central portion of the basin, with the minimum score in the municipality of Congo. The vegetation index was spatially and temporally heterogeneous, corresponding to regional climate characteristics. The dry year 2013 presented vegetation index values below the rainy year of 2008 , but still there is intra-annual and space-time variations. There were negative correlations between vegetation indexes and the air temperature, as well as positive correlations, most significantly, with pluvial precipitation.

Keywords: caatinga, rainfall, air temperature, remote sensing.

\section{Resumen}

Este estúdio tuvo como objetivo analizar la variación espacial-temporal del índice de vegetación de la diferencia normalizada (IVDN), del índice de vegetación ajustado al suelo (IVAS) y la relación con los parámetros climáticos en la cuenca del alto curso del Río Paraíba, que incluye la totalidad o parte, 18 condados, distribuidos en las microrregiones del Cariri Occidental y Oriental del estado de Paraíba. Fueron utilizadas 168 imágenes MODIS (Moderate Resolution Imaging Spectro Radiometer), correspondientes a los doce meses del año en el periodo de 2000 a 2013, para obtener los índices de vegetación que posteriormente fueron correlacionados con datos de precipitación pluvial y temperatura media del aire. Se utilizó el método kriging para espacialización de datos y generación de mapas temáticos. Los principales resultados muestran que los valores medios del índice de vegetación decrecen del noroeste y nordeste para la porción central de la cuenca, con valores mínimos en la ciudad de Congo. El índice de vegetación fue espacial y temporalmente heterogéneo, lo que corresponde a las características climáticas regionales. El año seco de 2013 presentó valores de índice de vegetación inferiores al año lluvioso de 2008, pero todavía hay variación espacio-temporal e intra-anual. Hubo correlaciones negativas entre los índices de vegetación y la temperatura del aire y las correlaciones positivas, más significativas, con la precipitación pluvial.

Palabras clave: caatinga, precipitaciones pluvial, temperatura del aire, teledetección.

\section{Introdução}

O Bioma Caatinga situa-se na faixa Equatorial e dispõe de abundante intensidade luminosa em todo seu território, durante todo o ano. As temperaturas são altas e pouco variáveis, espacial e temporalmente, com médias anuais entre $25^{\circ} \mathrm{C} \mathrm{e} 30^{\circ} \mathrm{C}$ e poucos graus de diferença entre as médias dos meses mais frios e mais quentes. Assim, luz e temperatura não são limitantes ao crescimento vegetal na área de Caatinga. A precipitação pluvial, por outro lado, é limitada e extremamente variável no tempo e no espaço. Essa variabilidade origina-se, dentre outras, das seguintes causas: (i) sistema muito complexo da formação das chuvas, com frentes que vem de vários quadrantes e que vão perdendo sua força à medida que penetram no núcleo do Semiárido. Como resultado, as chuvas são concentradas em poucos meses do ano e os anos chuvosos são alternados irregularmente com anos de secas; (ii) disposição orográfica, com serras e chapadas mais altas interceptando as frentes mais úmidas, recebendo mais chuvas que 
o entorno e criando zonas pouco chuvosas a sotavento (Sampaio, 2003; Sampaio, 2010; Ab' Saber, 2003).

A precipitação pluvial é uma das principais forças motrizes para a disponibilidade da biomassa em áreas secas e é, portanto, altamente correlacionada com a cobertura vegetal, tornando pastagens semiáridas um indicador sensível das mudanças climáticas e de uso e ocupação do solo em combinação com outros fatores, tais como: aumento da população, pressão dos rebanhos e mudanças climáticas, e a diminuição da vegetação que pode ocasionar a degradação das terras, esse é um problema ambiental crescente no semiárido brasileiro (Conti, 2005; Brasil, 2004; Souza et al., 2004; Souza et al.,2010; Alves et al.,2009). Nas áreas semiáridas, a vegetação e, portanto, os índices de vegetação, estão altamente correlacionados com a precipitação pluvial (Mao et al., 2012; Wang et al.,2001; He, 2014; Brinkmann et al., 2011).

Em virtude da importância e dos reduzidos dados de campo para monitorar a variação espaço-temporal da cobertura vegetal da Caatinga, pesquisas com sensoriamento remoto permitem compreender o comportamento de parâmetros biofísicos.

Estudos sobre o emprego de técnicas de sensoriamento remoto para análise da dinâmica da cobertura vegetal e avaliação das áreas com degradação das terras/desertificação são observados em: Li et al. (2000); Barbosa et al. (2006); Rodrigues et al. (2009); Lopes et al. (2010); Sá et al. (2010); Melo et al. (2011) e Aquino et al. (2012).

A análise da vegetação por meio de uma única imagem limita a extração de informações, pois ela representa a cena de uma única data da passagem do satélite. Contudo, a utilização de uma série multitemporal permite o acompanhamento da biomassa verde e da estrutura da vegetação. A identificação e eliminação dos fatores que contribuem para a degradação das terras é a forma mais eficaz de reverter os prejuízos ambientais, auxiliando no planejamento adequado dos recursos naturais disponíveis (Castanho et al., 2004; Magalhães et al., 2013; Bezerra et al., 2014).

De acordo com Ponzoni et al. (2012), diversos índices de vegetação têm sido propostos na literatura com o objetivo de explorar as propriedades espectrais da vegetação, especialmente nas regiões do visível e do infravermelho próximo. Esses índices são relacionados a parâmetros biofísicos da cobertura vegetal, como biomassa e índice de área foliar, declividade da superfície e geometria de aquisição, que influenciam os valores de 
refletância da vegetação. Os autores explicam ainda que quanto maior for a densidade da cobertura vegetal de uma determinada área, maior será a absortância na região do visível, em razão da maior oferta de pigmentos fotossintetizantes. Por outro lado, maior será a refletância verificada na região do infravermelho próximo, por causa do espalhamento múltiplo da radiação eletromagnética na estrutura foliar das plantas.

Os principais índices de vegetação disponíveis na literatura são: índice de vegetação da razão simples - IVRS, índice de vegetação da diferença normalizada - IVDN, índice de vegetação perpendicular - IVP, índice de vegetação ajustado para o solo - IVAS, índice de vegetação resistente à atmosfera - IVAA, índice global de monitoramento ambiental - IGMA e índice de vegetação melhorado - IVM (Accioly et al., 2002; Barbosa et al., 2006; Rodrigues et al., 2009; Cunha et al., 2012; Ponzoni et al.,2012). O IVDN e o IVAS são mais adequados para analisar a vegetação em regiões semiáridas e são mais identificados na literatura específica (Herrmann et al., 2005; Machado et al., 2011; Melo et al., 2011; Becerril-Piña et al., 2015).

Em geral, a mudança na vegetação é o indicador mais direto da degradação do solo causada pela desertificação. No entanto, não se recomenda uma avaliação baseada apenas nas mudanças do crescimento da vegetação, pois existem vários estados estáveis para a vegetação em ecossistemas áridos (Yang et al., 2004).

O Rio Paraíba e seus afluentes compõem uma importante bacia hidrográfica para o estado da Paraíba. O seu alto curso abrange os municípios das microrregiões do Cariri Ocidental e Oriental, localizados na região semiárida. Devido ao modelo de exploração estabelecido ao longo de décadas nessa região, os recursos naturais estão bastante degradados, limitando assim o desenvolvimento regional e local. Apesar da importância dessa região, existem poucos estudos para caracterizar, avaliar e monitorar a vegetação e consequentemente a degradação das terras nessa região. Assim, existe uma necessidade iminente de estudos sobre a cobertura vegetal em escala espaço-temporal, vislumbrando a mitigação dos impactos antropogênicos. Nesse contexto, o presente estudo teve como objetivo analisar a variação espaço-temporal do índice de vegetação e sua 
relação com parâmetros climáticos na bacia hidrográfica do alto curso do Rio Paraíba.

Materiais e Métodos

Área de estudo

O presente estudo foi realizado na bacia hidrográfica do alto curso do Rio Paraíba, quese limita ao Norte com a sub-bacia do Rio Taperoá, ao Sul e a Oeste com o estado de Pernambuco e a Leste com a região do médio curso do Rio Paraíba (Figura 1). A bacia hidrográfica do alto curso do Rio Paraíba tem uma área de aproximadamente $6.727,69 \mathrm{~km}^{2}$ e engloba, total ou parcialmente, a área de 18 municípios.

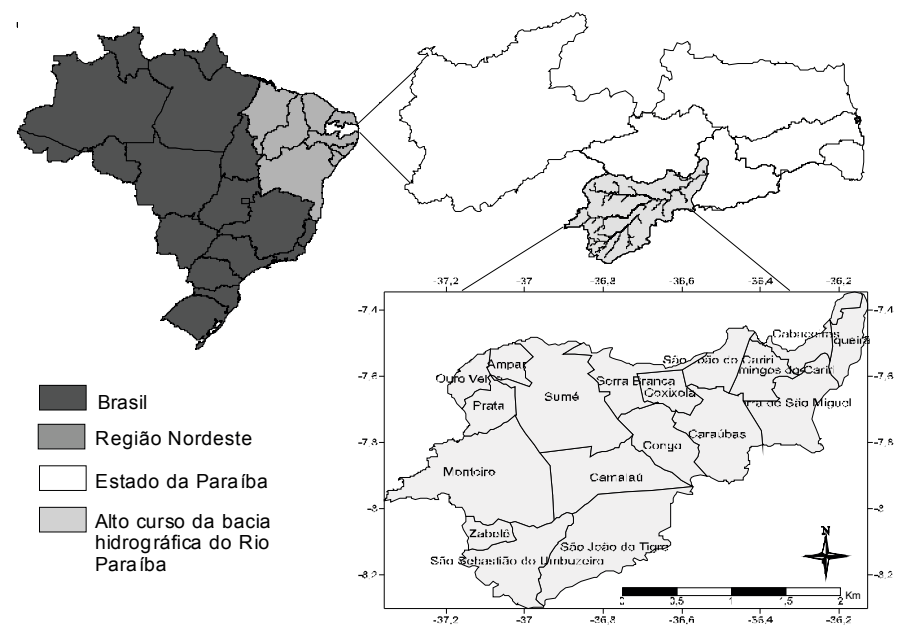

Figura 1 - Localização geográfica da bacia hidrográfica do alto curso do Rio Paraíba, estado da Paraíba

\section{Dados Climáticos}

Utilizou-se uma série de dados de precipitação pluvial e temperatura média do ar referente aos municípios, com período superior a 30 anos. Os dados foram obtidos junto a Unidade Acadêmica de Ciências Atmosféricas (UACA) da Universidade Federal de Campina Grande (UFCG). 
Quando não disponíveis, os valores (máximos, médios e mínimos) de temperatura do ar para os municípios foram estimados pelo modelo de regressão linear múltipla (Estima T), em função das coordenadas geográficas locais (latitude, longitude e altitude) e das anomalias de temperaturas da superfície do mar - ATSM, conforme Cavalcanti et al. (2006):

$$
T_{i j}=a_{0}+a_{1} \lambda+a_{2} \varphi+a_{3} h+a_{4} \lambda^{2}+a_{5} \varphi^{2}+a_{6} h^{2}+a_{7} \not \rho+a_{8} \lambda h+a_{9} \varphi h+\text { ATSM }_{j}
$$

Em que: $a_{0}, \ldots, \mathrm{a}_{9}$ são os coeficientes de regressão; $\lambda$ é a longitude; $\varphi$ é latitude e h a elevação, em metros. Os índices i e j indicam, respectivamente, o mês e o ano para o qual se está calculando a temperatura do ar (Tij). Assim, o sinal da temperatura da superfície do mar (ATSMij) assume valores positivos e negativos de acordo com o padrão de comportamento da TSM do oceano. As temperaturas médias, máximas e mínimas no nordeste do Brasil são melhores correlacionadas com as ATSM's do oceano Atlântico Sul.

Em relação à análise estatística, foi obtida a medida de tendência central (média)dos valores mensais e anuais da precipitação pluvial e da temperatura do ar para cada município e, posteriormente, a média referente à região do alto curso da bacia hidrográfica do Rio Paraíba.

\section{Dados orbitais}

Foram utilizadas imagens digitais orbitais MODIS (Moderate Resolution Imaging Spectro radiometer), para obtenção dos índices de vegetação, disponíveis em grande quantidade, pois a resolução temporal é diária. O sensor MODIS é um instrumento fundamental a bordo dos satélites Terra - Aqua.

As imagens foram obtidas gratuitamente no portal da National Aeronauticsand Space Administration - NASA⒈ Devido à oferta de um produto melhorado a cada oito dias optou-se pelo produto MOD09A1, considerado mais adequado para o monitoramento dos parâmetros estudados. Este produto é oriundo da refletância da superfície, disponível no MODLAND para o continente sul-americano.

Os dados MODIS foram obtidos originalmente na projeção integerized sinusoidale no formato Hierarquical Data Format (HDF), sendo convertidos para o sistema de coordenadas geográficas, projeção WGS, e formato IMG através do ERDAS Imagine 8.5. Além disso, todas as rotinas computacionais necessárias à geração dos índices de vegetação foram executadas no módulo Model Maker deste programa. A área de estudo está inserida no tile v9_h12. 
Foi analisado um Dia Juliano de cada mês; selecionados devido à ausência de nuvens e por representarem sequencialmente os meses da série temporal 2000-2013. As informações espectrais foram obtidas para cada município, por meio da delimitação dos mesmos, em formato AOI.

A Tabela 1 descreve o produto MODIS utilizado no presente estudo, com o fator de correção multiplicativo que é empregado para converter os valores originais em dados de refletância (adimensional):

Tabela 1- Descrição do produto MODIS utilizado

\begin{tabular}{ccccc}
\hline Produto & Descrição & $\begin{array}{c}\text { Fator } \\
\text { multiplicativo }\end{array}$ & $\begin{array}{c}\text { Resolução espacial } \\
\text { e temporal }\end{array}$ & Unidades \\
\hline MOD09A1 & $\begin{array}{c}\text { Reflectância } \\
\text { da superfície }\end{array}$ & 0,0001 & $\begin{array}{c}500 \mathrm{~m} \\
\text { diária/composição de 8 } \\
\text { dias }\end{array}$ & Adimensional \\
\hline
\end{tabular}

Fonte: http://modis.gsfc.nasa.gov/

\section{Índices de vegetação}

O índice de vegetação por diferença normalizada (IVDN), que varia de -1 a +1 ,sendo positivo para superfícies com alguma vegetação e negativo para superfícies livres de água (espelhos d'água), foi obtido como (PONZONI et al., 2012):

$$
I V D N=\frac{\left(\rho_{I V P}-\rho_{V}\right)}{\left(\rho_{I V P}+\rho_{V}\right)}
$$

Em que: $\rho_{\mathrm{IVP}}$ é a refletância medida na banda espectral do infravermelho próximo $(0,725-1,00 \mu \mathrm{m})$ e $\rho_{\mathrm{v}}$ a refletância medida na banda espectral do visível (vermelho) (0,625 - 0,725 $\mu \mathrm{m})$.

O índice de vegetação ajustado ao solo (IVAS) foi obtido como:

$$
I V A S=\frac{\left(\rho_{I V P}-\rho_{V}\right)(1+L)}{\left(\rho_{I V P}+\rho_{V}+L\right)}
$$

Em que: $\rho_{\mathrm{IVP}}$ é a refletância medida na banda espectral do infravermelho próximo $(0,725-1,00 \mu \mathrm{m})$ e $\rho_{\mathrm{v}}$ a refletância medida na banda espectral do visível (vermelho) $(0,625-0,725 \mu \mathrm{m})$ e L é a constante que minimiza o efeito do solo e pode variar de 0 a 1 . Neste caso foi utilizado o valor 
0,5. Para baixa, média e alta densidade de vegetação, recomendam-se os fatores $L=1, L=0,5$ e $L=0,25$, respectivamente (Ponzoni et al., 2012; Brinkmann et al., 2011).

\section{Mapas temáticos}

Neste trabalho, o sistema de informação geográfica (SIG) foi utilizado para a modelagem espacial dos valores da precipitação pluvial e do índice de vegetação ajustado ao solo, cujo método de interpolação utilizado foi o geoestatístico (krigagem). O método é baseado em modelos estatísticos que utilizam a autocorrelação, a fim de explicar a variação territorial. Este procedimento é utilizado para calcular o valor da variável climática a um dado ponto, considerando os valores de estações vizinhas a partir de um modelo de variograma para a variável considerada (Fitz, 2008).

O índice de vegetação permitiu comparar a cobertura vegetal atual com a vegetação pretérita, em uma análise de evolução temporal, considerando-se as características específicas da sazonalidade na área de estudo.

\section{Dados de campo}

As características da vegetação bem como o uso e ocupação do solo foram investigados por meio de visitas técnicas ao campo, com o intuito de selecionar pontos de controle que representassem a diversidade do que se estava investigando/mapeando. Este procedimento orientou a análise das imagens orbitais. Tais visitas foram realizadas em:

- Junho e dezembro de 2012: onde foram visitadas várias áreas nos municípios de Caraúbas, Congo, São Domingos do Cariri, Sumé, Camalaú e Monteiro.

- Abril de 2015: foi realizado trabalho de campo em todos os municípios, com o reconhecimento de aspectos da vegetação e georeferenciamento de áreas em processo de degradação. 


\section{Resultados e Discussão}

\section{Distribuição espacial e correlação das variáveis}

A distribuição espacial dos valores médios (2000-2013) do índice de vegetação (IVAS) é apresentada na Figura 2A. Observa-se que os valores decrescem de noroeste e nordeste para a porção central. O município de Congo apresenta os menores índices, o que pode estar relacionado com um uso inadequado do solo, bem como elevado quantitativo de rebanhos neste município, o que acentua o processo de degradação das terras. Os municípios de Amparo e Prata apresentam os picos, com valores máximos de vegetação.

A distribuição espacial da precipitação pluvial (Figura 2B) mostra que os valores mínimos da precipitação pluvial coincidem com os municípios de Cabaceiras e Caraúbas. Os valores máximos de precipitação plu(Âlilal são observados na porção noroestę)da bacia. Nessas áreas as altitudes são elevadas (600-700m) e a declividade mais acentuada (Figura 2C e 2D), localizando-se a nascente do Rio Paraíba, município de Monteiro. As porções nordeste e sudeste da bacia apresentam os menores valores de precipitação. Assim, observa-se uma variação crescente da precipitação pluvial entre o mínimo (320 mm) em Cabaceiras e um máximo (680 mm) nos municípios de Prata e Ouro Velho.

Corroborando com este resultado, Nascimento e Alves (2008) em estudo comparativo entre as microrregiões do Cariri Ocidental e Oriental do estaḑo da Paraíba concluíram que os municíppios do Cariri Oriental são mais atingidos por variações sazonais do regime pluviométrico, logo, mais secos.
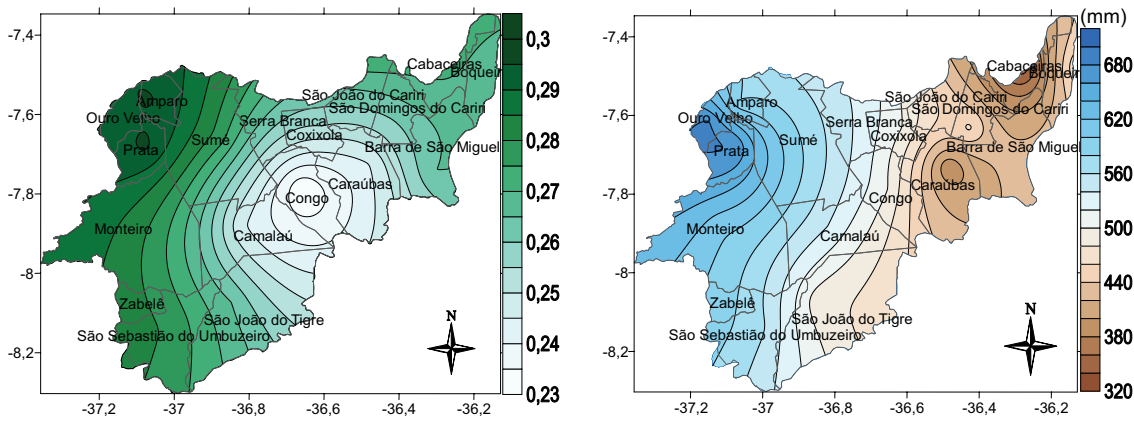


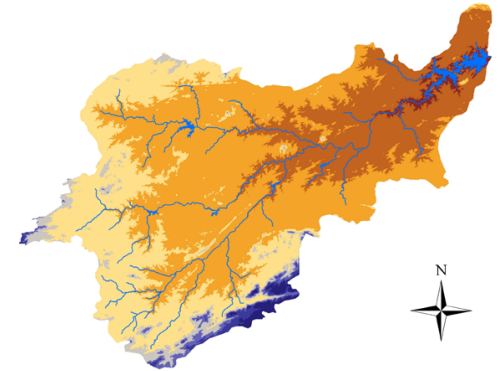

$\begin{array}{lllll}\text { Legenda } & \text { Altimetria (m) } & & \\ - \text { Rede de drenagem } & \square_{300-400} & \square_{500-600} & \square 700-800 & \square 900-1000 \\ \text { ICorpos hídricos } & \square 400-500 & \square 600-700 & \square 800-800 & \square 1000-1170\end{array}$

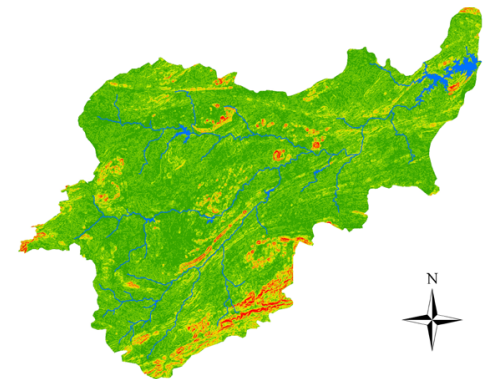

Legenda

- Rede de drenagem

Corpos hídricos

\section{Declividade (\%)}

10-3 (Plano) \20-45 (Forte ondulado)

3-8 (Suave ondulado) 45 - 75 (Montanhoso)

\8-20 (Ondulado)

Figura 2 - Distribuição espacial dos valores médios do Índice de vegetação ajustado ao solo - IVAS (A) da precipitação pluvial (B) altimetria (C) e declividade (D) no alto curso da bacia hidrográfica do Rio Paraíba.

É importante ressaltar que a cobertura vegetal da região em estudo é secundária, portanto mais esparsa, justificando em partes os valores mínimos de IVAS. Houve uma remoção da vegetação natural ao longo do tempo para o desenvolvimento da agricultura, utilização de lenha como fonte energética e, mais recentemente, um aumento significativo da pecuária extensiva. Essas práticas cumulativas resultaram em danos à vegetação e cenários de degradação das terras. De acordo com o PAEPARAÍBA PB (2011) cerca de 60\% e 70,7\% das áreas das microrregiões do Cariri Ocidental e Oriental, respectivamente, estão com alto nível de desertificação. Destaca-se os municípios de Caraúbas, Gurjão, Santo André, Barra de São Miguel, São José dos Cordeiros, Taperoá, Parari, Serra Branca, Coxixola, Congo, Camalaú e São João do Tigre como os municípios mais degradados. Nessas regiões ocorrem usos mais intensos das terras, seja agrícola ou com pecuária extensiva, e os valores de precipitação pluvial são mínimos, criando um ambiente de maior vulnerabilidade hídrica.

Quando analisados sazonal e intra-anualmente, os índices de vegetação variam de acordo com o período seco e chuvoso para a região (Figura 3). Essa constatação também foi demonstrada por Bezerra et al. (2014) ao identificarem, em região semiárida do Rio Grande do Norte, valores de IVDN entre 0,20 e 0,30 no período seco e 0,60 a 0,80 no período chuvoso. 
Os picos de índice de vegetação encontrados após o trimestre chuvoso (fevereiro-março-abril) são decorrentes do tempo (1-12 semanas) necessário para a recuperação do porte e densidade da vegetação (Mao et al. 2012; Govaerts e Lanttazio, 2008). Observa-se que os valores de IVDN são mais elevados que os do IVAS. Apesar de o primeiro ser amplamente utilizado pela comunidade científica, não leva em consideração os efeitos do solo na resposta espectral.

A compreensão desse comportamento similar entre a precipitação pluvial e a vegetação é importante para o planejamento das ações e intervenções no ambiente. Com a redução da biomassa a partir do mês de setembro, o solo fica desprotegido e suscetível ao processo de erosão e, havendo exploração antrópica nesse período, acentua-se a degradação das terras.

Na figura 4 observam-se as correlações dos índices de vegetação com as variáveis climáticas: precipitação pluvial e temperatura do ar. Há uma correlação decrescente entre os índices de vegetação e a temperatura do ar. Correlações crescentes e mais fortes $\left(\mathrm{R}^{2}=0,66\right.$ e $\left.\mathrm{R}^{2}=0,64\right)$ são observadas entre o IVAS e IVDN, respectivamente, e a precipitação pluvial.

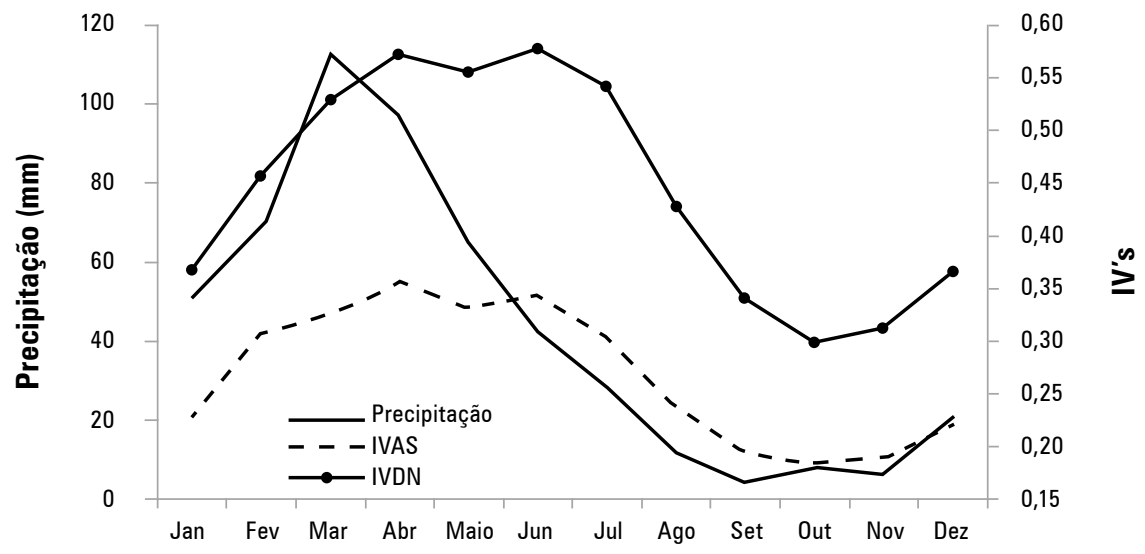

Figura 3 - Média mensal da precipitação pluvial e sua relação com os índices de vegetação por diferença normalizada (IVDN) e ajustada ao solo (IVAS) para a bacia hidrográfica do alto curso do Rio Paraíba

A elevação da temperatura aumenta a intensidade de transpiração vegetal e, diminuindo a precipitação, há redução na umidade disponível 
para as plantas (Mao et al., 2012, Yang et al., 2004). As correlações negativas entre os índices de vegetação e a temperatura do ar resultam das elevadas taxas dessa variável climática na região, em torno de $24{ }^{\circ} \mathrm{C}$, potencializando o processo de evapotranspiração, fazendo com que a vegetação típica de Caatinga perca suas folhas como estratégia de adaptação ao ambiente.

A correlação significativamente positiva entre os índices de vegetação e a precipitação pluvial é causada pelo fornecimento de umidade, necessária para o crescimento da vegetação. Resultados semelhantes são encontrados em Herrmann et al. (2005). A precipitação que ocorre no verão e outono na região em estudo beneficia o crescimento da vegetação.

Muitas paisagens áridas e semiáridas são caracterizadas por sistemas onde a produtividade da planta é largamente dependente do escoamento superficial das áreas desprotegidas por fragmentos de vegetação (Brinkmann et al., 2011). Isso normalmente resulta em um mosaico, ou padrão composto de porções com alta densidade de vegetação alternando com manchas de uma baixa cobertura vegetal ou mesmo solo descoberto.
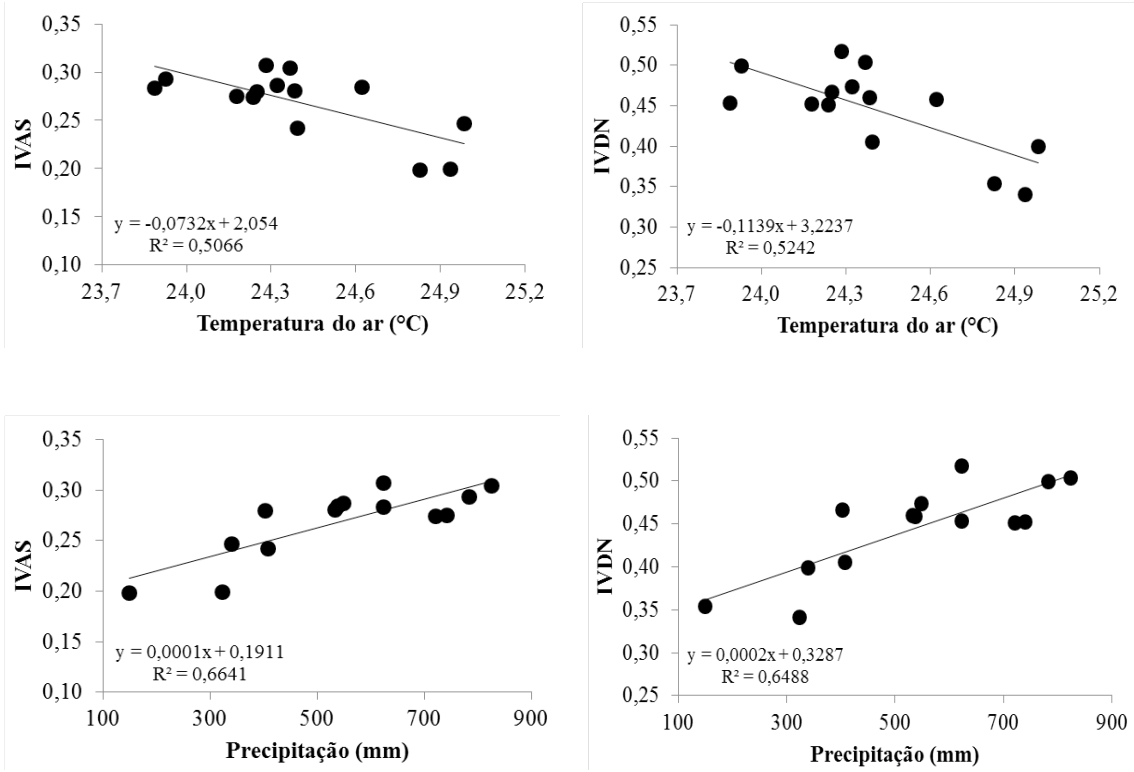

Figura 4 - Correlação entre a o índice de vegetação ajustado ao solo (IVAS) e a temperatura média do ar (A) e a precipitação pluvial média $(B)$ e do índice de vegetação por diferença normalizada (IVDN) e a temperatura média do ar (C) e a precipitação pluvial média (D). 


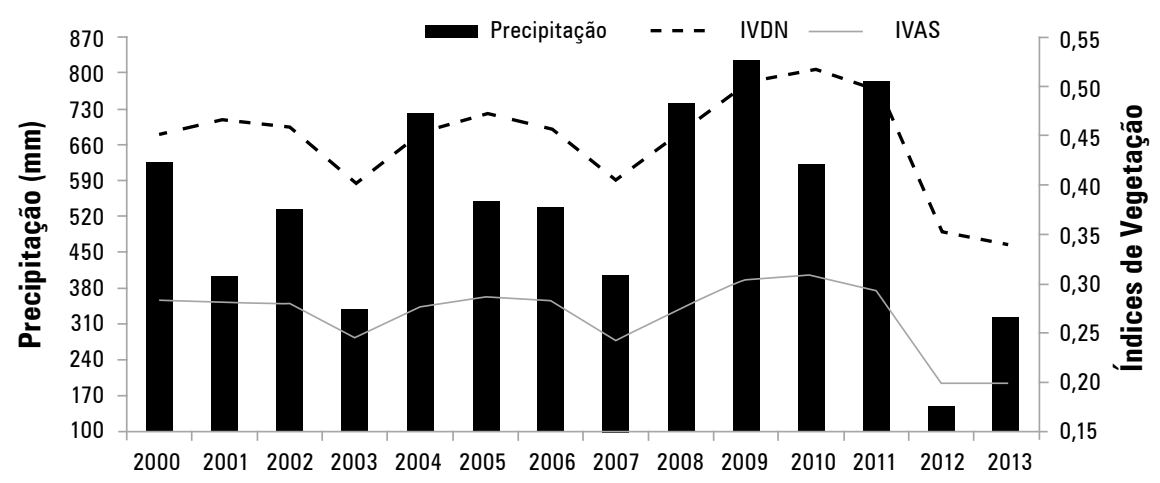

Figura 5 - Distribuição temporal da precipitação pluvial média (barras) e dos índices de vegetação por diferença normalizada (IVDN) e ajustada ao solo (IVAS) na bacia hidrográfica do alto curso do Rio Paraíba

Na figura 5 observa-se o comportamento dos índices de vegetação por diferença normalizada (IVDN), ajustado ao solo (IVAS) e sua relação com a precipitação pluvial no período de 2000 a 2013. Observa-se que as curvas de valores mínimos coincidem com os anos em que a precipitação pluvial esteve abaixo da média para a região $(450 \mathrm{~mm})$. Os picos estão relacionados com a maior ocorrência de precipitações.

$\mathrm{O}$ ano para o qual os valores dos índices médios de vegetação foram mais elevados (IVDN $=0,53$ e IVAS $=0,31$ ) foi 2010 , cujo maior valor ocorreu no mês de abril. Neste ano ocorreu o único evento de La Niña forte para o período estudado. O ano com menores índices de vegetação foi 2013 (0,34 e 0,20, para o IVDN e IVAS, respectivamente), com ocorrência nos meses de outubro e setembro. Esse ano foi caracterizado por apresentar El Nino muito fraco, com precipitações abaixo da média.

Observa-se na figura 6 que não foi identificado padrão semelhante no comportamento dos índices de vegetação e da temperatura média do ar. A variabilidade intra e interanual da temperatura na região é mínima, cerca de $1{ }^{\circ} \mathrm{C}$. No entanto, é possível perceber que picos de temperatura coincidem com os valores mínimos dos índices de vegetação, anos de 2003, 2012 e 2013. Tais anos apresentaram precipitações abaixo da média, contribuindo para que não houvesse suavização nos valores de temperatura do ar. 


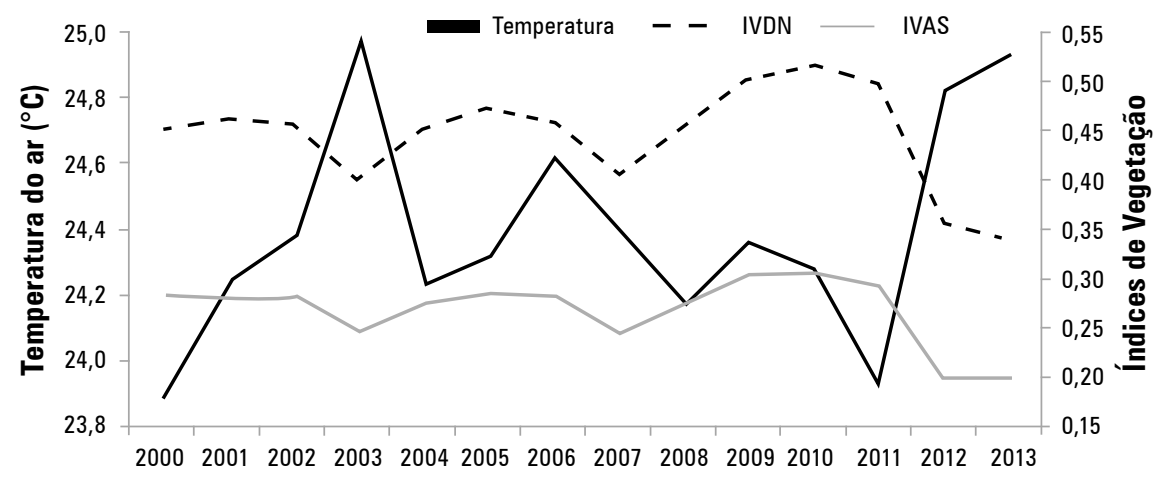

Figura 6 - Distribuição temporal da temperatura média do ar e dos índices de vegetação por diferença normalizada (IVDN) e ajustada ao solo (IVAS) na bacia hidrográfica do alto curso do Rio Paraíba

A temperatura influencia o crescimento e o desenvolvimento das plantas. A germinação, floração e frutificação são processos influenciados pela temperatura ambiental. Cada espécie, no entanto, tem uma temperatura ótima para realização de seus processos.

He (2014) observou que a porcentagem de cobertura vegetal diminuiu nos anos com precipitação moderada e alta temperatura em região semiárida, o que sugere que um declínio na disponibilidade de água, causada por uma combinação de redução da precipitação e aumento da evapotranspiração, leva a uma perda de cobertura vegetal.

Distribuição espacial do índice de vegetação ajustado ao solo para o ano seco e chuvoso

As Figuras 7 e 8 referem-se à distribuição mensal do índice de vegetação ajustado ao solo (IVAS) para o ano seco (2013) e chuvoso (2008), respectivamente. Em relação à imagem do dia 30/09 (Figura 7) observa-se que mais de $50 \%$ da área apresenta IVAS entre 0,08 e 0,16. Tal evidência relaciona-se a época de imageamento da região, que corresponde ao período de precipitações pluviais mínimas, e também devido à própria vegetação da área, formada por caatinga caducifólia arbustiva, que se caracteriza pela queda das folhas no período seco (agosto a dezembro).

É importante destacar que nos meses de maio, junho e julho, a presença de vegetação está mais concentrada nas proximidades do 
reservatório hídrico "Epitácio Pessoa” (município de Boqueirão) e na Área de Proteção Ambiental (APA) das Onças, (município de São João do Tigre). No primeiro caso a explicação está relacionada à existência de áreas irrigadas com desenvolvimento permanente de culturas no entorno do reservatório, não correspondendo à existência de vegetação nativa. No segundo caso a razão explicativa é o relevo, pois coincide com as áreas mais elevadas e com maior declividade, sendo o acesso e a utilização dessas áreas para fins agropecuários mais limitados. Quando avaliado temporalmente, o IVAS pode ser importante indicador de desertificação e de redução de fitomassa da Caatinga (Sampaio et al., 2003; Rodrigues et al., 2009).

Os municípios que apresentaram menores índices de vegetação foram Congo, Caraúbas e Camalaú. Certamente nestes municípios, as ações antrópicas relacionadas à degradação das terras são mais acentuadas. Nesses municípios ocorrem as maiores áreas de solo exposto (IVAS entre 0,0 e 0,16 ) e vegetação arbustiva aberta baixa (IVAS entre 0,16 e 0,24). É necessário que haja um uso mais racional do solo nesses municípios, que vise à conservação da cobertura vegetal. Mafra (2014) relaciona o menor aporte de matéria orgânica, a compactação do solo, a mineralização da matéria orgânica, a menor infiltração, maior escoamento superficial e maior erosão como consequências da eliminação da cobertura vegetal, do cultivo intensivo e do superpastoreio.

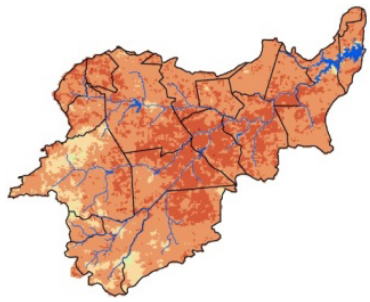

$25 / 01$

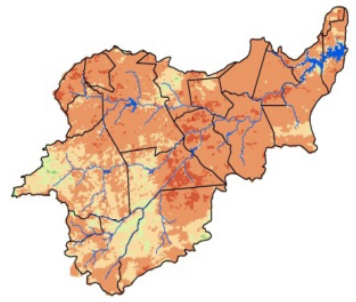

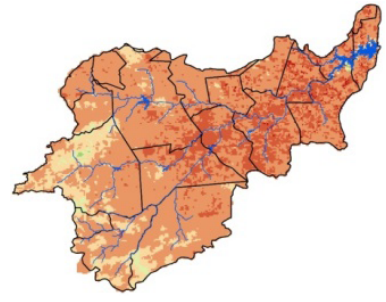

$02 / 02$

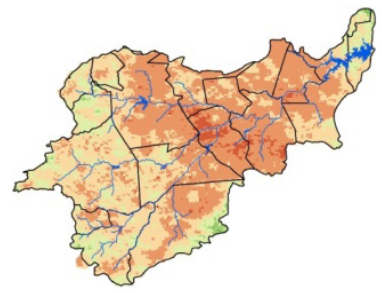

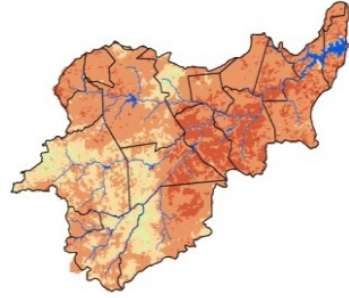

$30 / 03$

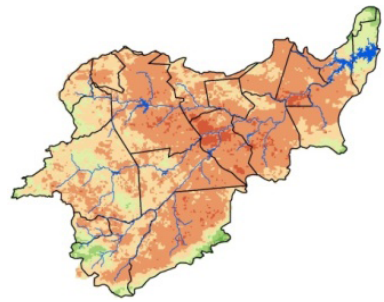




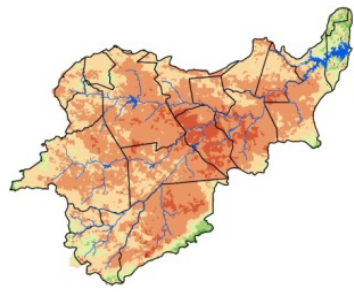

$20 / 07$

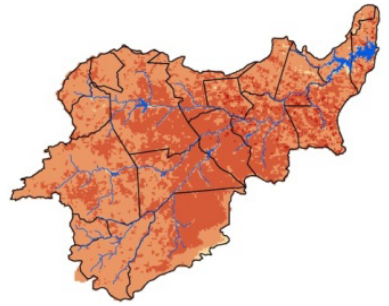

$08 / 10$

$09 / 11$

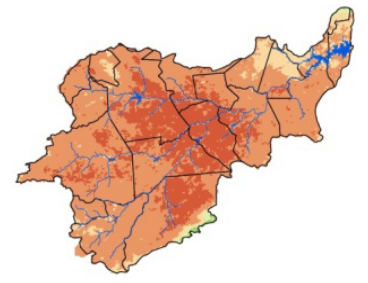

$21 / 08$

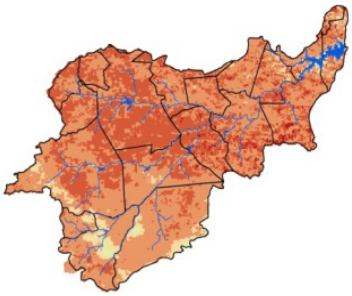

Legenda

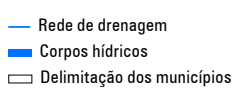

$$
\begin{array}{rr}
\square 0,16-0,24 & \square 0,40-0,48 \\
\square 0,24-0,32 & \square, 48-0,56 \\
\square 0,32-0,40 & 0,56-0,64
\end{array}
$$

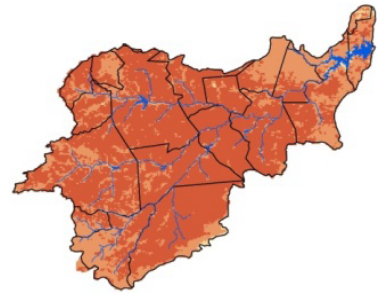

$30 / 09$

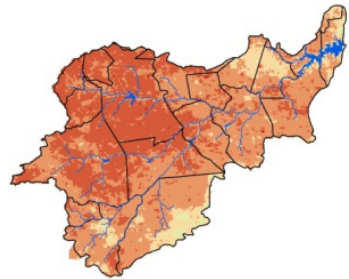

$03 / 12$

Figura 7 - Carta temática do comportamento sazonal do índice de vegetação ajustado ao solo (IVAS) da bacia hidrográfica do alto curso do Rio Paraíba, durante 0 ano de 2013

Na Figura 8 observa-se a caracterização da vegetação no ano chuvoso de 2008. Na imagem do dia 06/04 verifica-se que $38 \%$ da área apresentou valores de IVAS entre 0,48 e 0,56 e 36\% valores entre 0,40 e 0,48, demonstrando uma vegetação de porte mais arbóreo e principalmente em condições mais favoráveis de suprimento hídrico, portanto com maior vigor, uma vez que a imagem foi obtida no período da estação chuvosa. Esse comportamento permanece até os meses de maio e junho. Govaerts e Lanttazio (2008) explicam que na relação entre vegetação e a precipitação há um atraso de cerca de um mês na resposta da vegetação à variação da umidade do solo, resultante da acumulação de água no sistema radicular da planta. Ressalta-se a importância de demonstrar o comportamento sazonal do índice de vegetação devido à predominância de meses secos influenciarem o valor médio apresentado. 


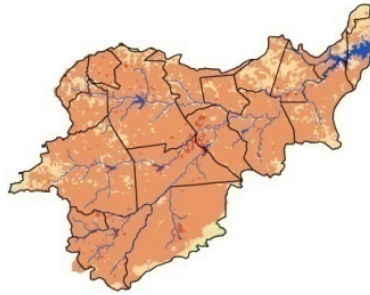

01/01

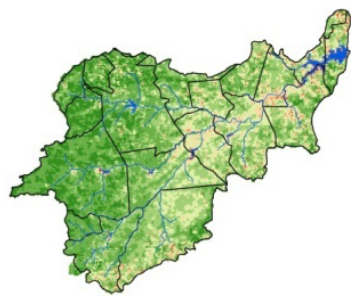

06/04

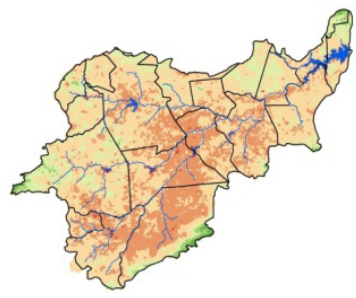

$20 / 08$

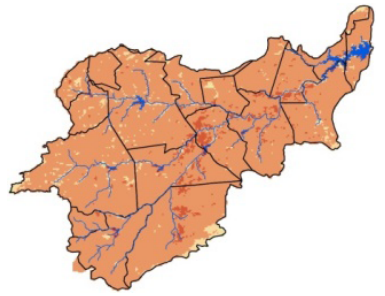

23/10

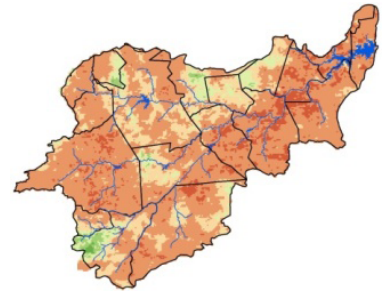

$02 / 02$

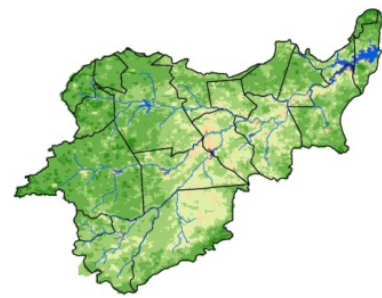

17/06

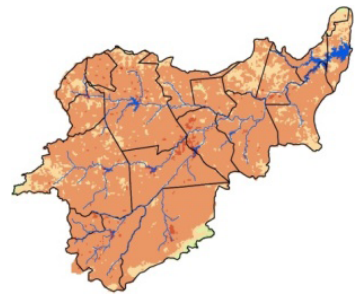

$21 / 09$

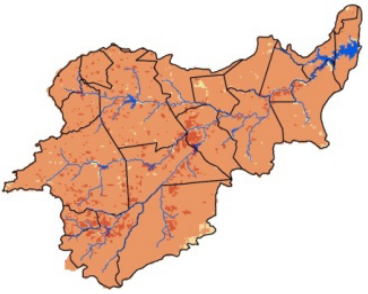

$16 / 11$

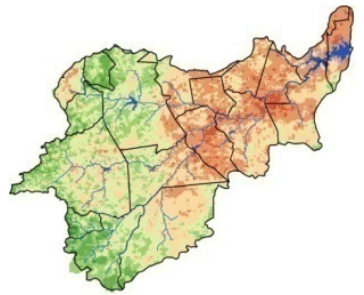

05/03

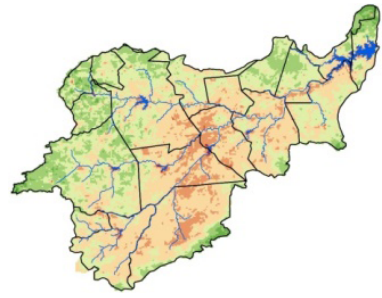

27/07

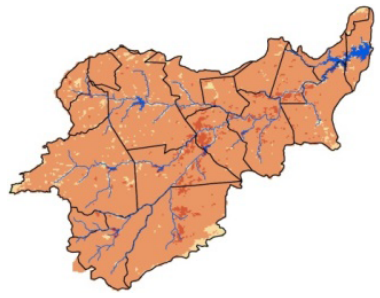

$23 / 10$

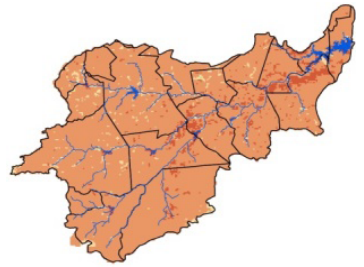

$10 / 12$

Legenda
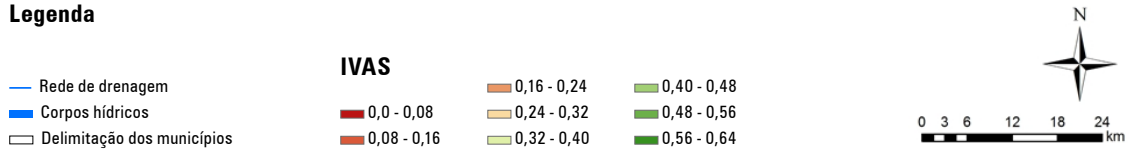

Figura 8 - Carta temática do comportamento sazonal do Índice de vegetação ajustado ao solo IVAS no alto curso da bacia hidrográfica do Rio Paraíba, durante 0 ano de 2008 
É importante mencionar que alguns casos em que o índice de vegetação é elevado, corresponde a campos de ProsopisJuliflora ( $\mathrm{Sw}$ ) (algaroba), uma vez que o IVAS assim como os demais índices de vegetação não envolve detecção de mudanças de composição de espécies. Tal constatação só foi possível através do trabalho de campo, que permitiu uma melhor interpretaçãodos dados obtidos com o sensoriamento remoto. A algaroba (Figura 9A) é uma espécie exótica, introduzida no bioma Caatinga e que apresentou elevada adaptabilidade à região, devido a um sistema radicular que se aprofunda no solo por vários metros e que é especializado em aproveitar a água armazenada nessa região. Essa espécie tem competido com o desenvolvimento de espécies nativas, especialmente em regiões de planícies aluviais. Em estudo realizado no semiárido, foram constatados pontos isolados que apresentaram IVDN próximos a 0,80 e que representam espécies nativas e exóticas, como o Zizyphusjoazeiro Mart (Juazeiro) e a Prosopis juliflora, que apresentam alta densidade foliar (Rodrigues et al., 2009).

Gallahere Merlin (2010), em estudo realizado no Havaí, relatam tanto impactos negativos quanto positivos da algaroba sobre o ambiente, estes últimos particularmente sobre áreas degradadas, são reconhecidos por facilitar o processo de sucessão vegetal, sendo seu uso indicado em esforços de reflorestamento. Nota-se, contudo, que os algarobais se concentram em solos aluviais, que correspondem, na maioria dos casos, a áreas agrícolas que foram abandonadas e rapidamente ocupadas por essa espécie, e que deveriam ter a mata ciliar nativa preservada.

Por meio dos resultados dos levantamentos de campo identificou-se em grande quantidade e em praticamente todos os municípios, algumas das espécies reconhecidas como predominantes nas áreas em processo de desertificação, são elas: Caesalpinia pyramidalis (Catingueira), Mimosa hostilis (Jurema preta), dentre outras, conforme Galindo et al. (2008), além de muitas áreas com presença de solo exposto (Figura 9B).

Para Araújo et al. (2014), as secas disparam o processo de degradação das terras, considerando que o pastoreio em terras secas tende a aumentar durante os anos de precipitação normal, e esse número excessivo é para ser suportado durante os anos de seca, até que lentamente o rebanho diminua.

O comparativo da sazonalidade da vegetação (Figuras 9C e 9D) mostra uma recuperação da folhagem da vegetação em decorrência do período chuvoso, também observada durante os levantamentos de campo. Como o crescimento e o desenvolvimento das plantas dependem de fatores 
abióticos (temperatura, luz, umidade etc.) fica nítida a recuperação das espécies vegetais quando esses fatores não são tão adversos.

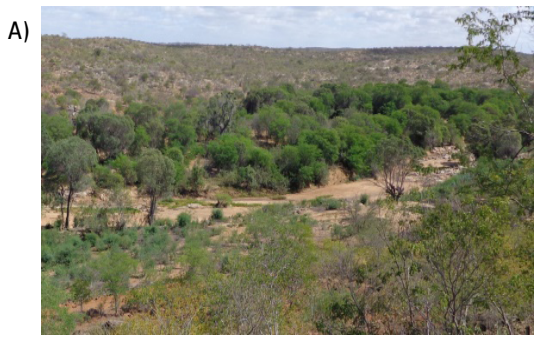

C)

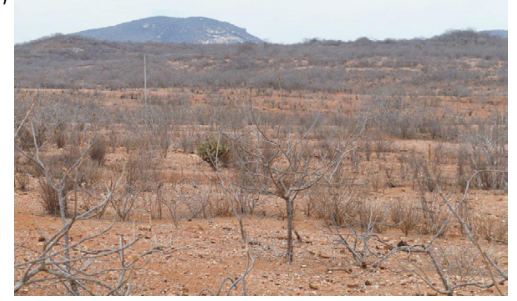

B)

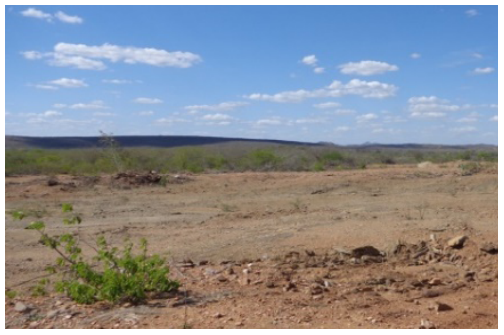

D)

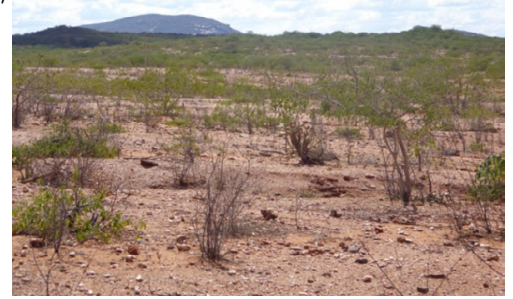

Figura 9 - Presença de algaroba nas margens do Rio Paraíba, município de Caraúbas-PB. (A) áreas de solo exposto no município de Congo-PB (B), vegetação de caatinga no período seco (dezembro/2012), Caraúbas-PB (C) e recuperação do dossel da vegetação de Caatinga no período chuvoso, Caraúbas-PB (abril/2015). Trabalho de campo realizado em 2012 e 2015

Tatagiba et al. (2007) explicam que o decréscimo do teor de água no solo diminui o potencial hídrico na folha (turgidez celular), contribuindo para diminuição da condutância estomática, e promovendo o fechamento parcial ou total dos estômatos. As reduções na biomassa das folhas e área foliar das plantas são resultado da queda das folhas, a depender da intensidade do déficit hídrico.

Crayn et al. (2004) relatam forte correlação entre a aridez e a ocorrência de plantas CAM. As plantas CAM ou MAC (Metabolismo Ácido Crassuláceo) abrem os estômatos à noite, quando a temperatura e evapotranspiração diminuem. Durante o dia os estômatos permanecem fechados e o carbono acumulado é utilizado na fotossíntese, aumentando a eficiência na utilização da água. 
Considerações finais

A análise da variação espaço-temporal,com base nas sequências mensais do índice de vegetação por diferença normalizada (IVDN) e ajustada ao solo (IVAS) - período de 2000 a 2013 - e sua relação com parâmetros climáticos na bacia hidrográfica do alto curso do Rio Paraíba, permitem concluir que houve correlações negativas entre os índices de vegetação e a temperatura média do ar e correlações positivas, mais significativas, com a precipitação pluvial, evidenciando que esta variável climática condiciona o desenvolvimento da vegetação na região.

Os valores médios do IVAS decrescem de noroeste e nordeste para a porção central da bacia e os índices mínimos foram identificados para o município de Congo, indicando possível degradação das terras. Os valores mínimos da precipitação pluvial coincidem com os municípios de Cabaceiras e Caraúbas. Os índices de vegetação foram heterogêneos, espacial e temporalmente, o que corresponde às características climáticas regionais. O ano seco de 2013 apresentou valores de IVAS bem inferiores ao ano chuvoso de 2008, mas ainda assim apresentou variação espaçotemporal intra-anual.

Na região semiárida do alto curso da bacia hidrográfica do Rio Paraíba as ações antrópicas devem ser bem planejadas para evitar a degradação das terras. Os resultados apresentados neste estudo oferecem subsídios para minimizar os impactos das intervenções e pressões antrópicas, principalmente nos períodos da estação seca, em que a vegetação perde suas folhas e o solo fica desprotegido, visando à conservação dos recursos naturais.

\section{Agradecimento}

Ao Conselho Nacional de Desenvolvimento Científico e Tecnológico - CNPq pela concessão de bolsa de doutorado da primeira autora.

\section{Nota}

${ }^{1}$ Disponível em:<http://earthexplorer.usgs.gov/>. 


\section{Referências}

AB'SABER, A. N. Os domínios de Natureza no Brasil: potencialidades paisagísticas. 2. ed. São Paulo: Ateliê Editorial, 2003. 158 p.

ACCIOLY, L.J.O.; PACHECO, A.; COSTA, T.C.C.; LOPES, O.F.; OLIVEIRA, M.A.J. Relações empíricas entre a estrutura da vegetação e dados do sensor TM/ LANDSAT. Revista Brasileira de Engenharia Agrícola e Ambiental, Campina Grande, v. 6, n. 3, 2002. p. 492-498.

ALVES, J. J. A.; SOUZA, E. N.; NASCIMENTO, S. S. Núcleos de desertificação no estado da Paraíba. Revista RA'EGA,Curitiba,n. 17, 2009. p. 139-152.

AQUINO, C. M. S.; ALMEIDA, J. A. P.; OLIVEIRA, J. G. B.Estudo da cobertura vegetal/uso da terra nos anos de 1987 e 2007 no núcleo de degradação/ desertificação de São Raimundo Nonato - Piauí. Revista RA'EGA,Curitiba,v. 25, 2012. p. 252-278..

ARAÚJO, G. H.S.; ALMEIDA, J. R. de; GUERRA, A. J. T. Gestão ambiental de áreas degradadas. Rio de Janeiro: Bertrand Brasil, 2014. 322 p.

BARBOSA, H. A.; HUETE, A.R.; BAETHGEN, W.E. A 20-years study of NDVI variability over the Northeast Region of Brazil. Journal of Arid Environments, v. 67, 2006. p. 288-307.

BECERRIL-PIÑA, R.; MASTACHI-LOZA, C.A.; GONZALEZ-SOSA, E.; DÍAZDELGADO, C.; KHALIDOU, M. Assessing desertification risk in the semi-arid highlands of central Mexico. JournalofAridEnvironments, v. 120, 2015. p. 4-13.

BEZERRA, J. M.; MOURA, G. B. de A.; SILVA, B. B. da; LOPES, P. M. O.; SILVA, E. F. de F. Parâmetros biofísicos obtidos por sensoriamento remoto em região semiárida do estado do Rio Grande do Norte, Brasil. Revista Brasileira de Engenharia Agrícola e Ambiental, v. 18, n. 1, 2014. p. 73-84.

BRASIL. Ministério do Meio Ambiente (MMA). Programa de Ação Nacional de Combate à Desertificação e Mitigação dos Efeitos da Seca, PAN-BRASIL. Convenção das Nações Unidades de Combate à Desertificação e Mitigação dos Efeitos da Seca - CCD. Brasília: MMA, 2004. 225 p.

BRINKMANN, K.; DICKHOEFER, U.; SCHLECHT, E.; BUERKER, A. Quantification of aboveground rangeland productivity and anthropogenic degradation on the Arabian Peninsula using Landsat imagery and field inventory data. Remote Sensingof Environment, v. 115, 2011. p. 465-474, 2011.

CAVALCANTI, E. P.; SILVA, V. P. R.; SOUSA, F. A. S. Programa computacional para a estimativa da temperatura do ar para a região Nordeste do Brasil. Revista Brasileira de Engenharia Agrícola e Ambiental, Brasil, v. 10, n. 1, 2006. p. 140-147.

CASTANHO, R. B.; CASSOL, R.; BEZZI, M. L. A modernização agrícola e o uso de técnicas de geoprocessamento no uso da terra em dois distritos de Palmeira das Missões-RS. Geosul, v. 19, n. 38, 2004. p. 159-183.

CONTI, J. B. A questão climática do nordeste brasileiro e os processos de desertificação. Revista Brasileira de Climatologia,v. 1, n. 1, 2005. p. 7-14. 
CRAYN, D. M.; WINTER, K.; SMITH, J. A. C. Multiple origins of crassulacean acid metabolism and the epiphytic habit in the Neotropical family Bromeliaceae. PNAS, v.101, n. 10, 2004. p. 3703-3708.

CUNHA, J. E. B. L.; RUFINO, I. A. A; SILVA, B. B; CHAVES, I. B. Dinâmica da cobertura vegetal para a Bacia de São João do Rio do Peixe, PB, utilizando-se sensoriamento remoto. Revista Brasileira de Engenharia Agrícola e Ambiental, v.16, n.5, 2012. p. 539-548.

FITZ, P. R. Geoprocessamento sem complicação. São Paulo: Oficina de textos, 2008. 158 p.

GALINDO, I. C. L.; RIBEIRO, M. R.; SANTOS, M. F. A. V.; LIMA, J. F. W. F.; FERREIRA, R. F. A. L. Relações solo-vegetação em áreas sob processo de desertificação no município de Jataúba, PE. Revista Brasileira de Ciência do Solo, v. 32, n.3, 2008. p. 1283-1296.

GALLAHER, T.;MERLIN,M.BiologyandImpactsofPacificIslandInvasiveSpecies. 6. Prosopispallida and Prosopisjuliflora (Algarroba, Mesquite, Kiawe) (Fabaceae). Pacific Science, v. 64, 2010. p. 489-526.

GOVAERTS, Y.; LATTANZIO, A. Estimation of surface albedo increase during the eighties Sahel drought from Meteosatobservations. Global and Planetary Change, v. 64, n. 3, 2008. p. 139-145.

HE, Y. The effect of precipitation on vegetation cover over three landscape units in a protected semi-arid grassland: Temporal dynamics and suitable climatic index. Journal of Arid Environments, v. 109, 2014. p. 74-82.

HERRMANN, S. M.; ANYAMBA, A.; TUCKER, C. J. Recent trends in vegetation dynamics in the African Sahel and their relationship to climate. Global Environmental Change, v. 15, 2005. p. 394-404.

LI, S. G.; HARAZONO, Y.; OIKAWA, T.; ZHAO, H. L.; HE, Z. Y.; CHANG, X. L. Grass land desertification by grazingand the resulting micrometeorological changes in Inner Mongolia. Agriculturaland Forest Meteorology, v. 102, 2000. p. 125-137.

LOPES, H.; CANDEIAS, A. L. B.; ACCIOLY, L.J.O.; SOBRAL, M. C. M.; PACHECO, A.P. Parâmetros biofísicos na detecção de mudanças na cobertura e uso do solo em bacias hidrográficas. Revista Brasileira de Engenharia Agrícola e Ambiental, v.14, n.11, 2010. p. 1210-1219.

MACHADO, C. C. C.; GALVÍNCIO, J. D.; OLIVEIRA, T. H. Análise espacial e temporal do IVAS e do albedo da superfície no município de São José do Sabugi - PB.Geografia, v. 36, n. 2, 2011. p. 359-369.

MAFRA, N. M. C. Erosão e Planificação de uso do solo. In: GUERRA, A. J. T.; SILVA, A. S. da; BOTELHO, R. G. M. Erosão e conservação dos solos. 9 ed. Rio de janeiro: Bertrand Brasil, 2014. 340 p.

MAGAlHÃES, I. A. L.; XAVIER, A. C.; SANTOS, A. R. Caracterização da dinâmica espectro temporal florestal e da cana-de-açúcar no município de Itapemirim, ES. Geosul, v. 20, n.39, 2013. p. 65-82. 
MAO, D.; WANG, Z.; LUO, L.; REN, C. Integrating AVHRR and MODIS data to monitor NDVI changes and their relationships with climatic parameters in Northeast China. International Journal of Applied Earth Observation and Geoinformation, v.18, 2012. p. 528-53.

MELO, E. T.; SALES, M. C. L.; OLIVEIRA, J. G. B. Aplicação do Índice de Vegetação por Diferença Normalizada (NDVI) para análise da degradação ambiental da microbacia hidrográfica do Riacho dos Cavalos, Crateús-CE. Revista RA'EGA, Curitiba, v.23, 2011. p. 520-533.

MODIS. Moderate Resolution Imaging Spectro radiometer. Modis Land. Disponível em: <http://modis.gsfc.nasa.gov/>. Acesso em: 10 maio 2014.

NASCIMENTO, S. S.; ALVES, J. J. A. Ecoclimatologia do Cariri Paraibano. Revista Geográfica Acadêmica, v. 2, 2008. p. 28-41.

PAE-PARAÍBA - PB. Programa de Ação Estadual de Combate à desertificação e Mitigação dos Efeitos da Seca no Estado da Paraíba. João Pessoa: Secretaria de Estado dos Recursos Hídricos, MMA/MCTI/ SUDEMA, 2011. 144 p.

PONZONI, F. J.; SHIMABUKURO, Y. E.; KUPLICH, T. M. Sensoriamento remoto da vegetação. 2 ed. São Paulo: Oficina de Textos, 2012. 160 p.

RODRIGUES, J. O.; ANDRADE, E. M.; TEIXEIRA, A. S.; SILVA, B. B. da. Sazonalidade de variáveis biofísicas em regiões semiáridas pelo emprego do sensoriamento remoto. Revista Brasileira de Engenharia Agrícola e Ambiental, v. 29, n. 3, 2009. p. 452-465.

SÁ, I. I. S.; GALVÍNCIO, J. D.; MOURA, M.S.B.; SÁ, I. B. Cobertura vegetal e uso da terra na região Araripe pernambucana. Mercator, v. 9, n. 19, 2010.

SAMPAIO, E. V. S. B. Caracterização da caatinga e fatores ambientais que afetam a ecologia das plantas lenhosas. In: SALES, V. C. (Org.). Ecossistemas brasileiros: manejo e conservação. Fortaleza: ExpressãoGráfica e Editora, 2003. p. 129-142.

. Características e Potencialidades. In: GARIGLIO, M. A. et al. (Org.) Uso sustentável e conservação dos recursos florestais da caatinga. Brasília: Serviço Florestal Brasileiro, 2010.

SOUZA, B. I.; SUERTEGARAY, D. M. A.; LIMA, E. R. V.Políticas Públicas, uso do solo e desertificação nos Cariris Velhos (PB/Brasil). Scripta Nova, v. 14, v. 311, 2010.

SOUZA, B. I.; SILANS, A. M. B. P.; SANTOS, J. B. Contribuição ao estudo da desertificação na Bacia do Taperoá. Revista Brasileira de Engenharia Agrícola e Ambiental. v. 8, n. 2-3, 2004. p. 292-298.

TATAGIBA, S. D.; PEZZOPANE, J. E. M.; REIS, E. F. Avaliação do crescimento e produção de clones de Eucalyptus submetidos a diferentes manejos de irrigação. Cerne, Lavras, v. 13, n. 1, 2007. p. 1-9.

WANG, J.; PRICE, K. P.; RICH, P. M. Spatial patterns of NDVI in response to precipitation and temperature in the central Great Plains. International Journal of Remote Sensing, v. 22, 2001. p. 3827-3844. 
YANG, X.; ROST, K.T.; LEHMKUHL, K. ; ZHU, Z. The evolution of dry lands in northern China and in the Republic of Mongolia since the Last Glacial Maximum. Quaternary International, v.118-119, 2004. p. 69-85.

Telma Lucia Bezerra Alves - Possui Graduação em Geografia pela Universidade Estadual da Paraíba e Mestrado em Recursos Naturais pela Universidade Federal de Campina Grande. Atualmente é Doutoranda em Recursos Naturais pela Universidade Federal de Campina Grande.

Pedro Vieira de Azevedo - Possui Graduação em Agronomia pela Universidade Federal da Paraíba, Mestrado em Meteorologia pelo Instituto Nacional de Pesquisas Espaciais e Doutorado em Bioengenharia - University of Nebraska-Lincoln. Atualmente é professor da Unidade Acadêmica de Ciências Atmosféricas - UACA, Universidade Federal de Campina Grande - UFCG.

Recebido para publicação em 12 de julho de 2015

Aceito para publicação em 29 de agosto de 2015 